\title{
“HACER LOS SUEÑos". UNA PERSPECTIVA WAYUU
}

\author{
“MAKE DreAms". \\ A Wayuu Perspective
}

\section{Carmen Laura Paz Reverol ${ }^{1}$}

Para ser wayuu hay que nacer de un vientre wayuu, soy wayuu porque nací de una madre wayuu, heredé de ella valores, normas, creencias y prácticas que me hacen wayuu. Pertenezco a la Península de la Guajira y a su gente. Es un medio inhóspito donde escasea el agua y donde las distancias son largas y el sol abrasador. Hay también parajes hermosos, playas llenas de misterio. La tierra Guajira despierta en mí sensaciones porque $m m a$ - la tierra - forma parte de mi historia personal, es mi matria como la madre que me parió.

No puedo sustraerme a esta realidad. Pero también me formé como antropóloga en Barcelona con la ayuda de Gemma Orobitg. Esto me coloca en una situación singular. Tiene ventajas e inconvenientes. Las ventajas: hablar el idioma wayuunaiki, conocer a mis parientes, tanto a mis apüshii o familiares por vía materna, como a mis o'upayuu o familiares por vía paterna. También mis parientes de eirrükü o clan, es decir, todo el que sea ipuana debe ser considerado como de mi familia. Me resulta familiar el respeto y la consideración que se le debe a todo wayuu, el cual debe ser tratado con las maneras wayuu,

\footnotetext{
${ }^{1}$ Universidad de Zulia, Maracaibo, Venezuela. Líneas de investigación: problemática de las Identidades, sistemas socioculturales y cuidado de las enfermedades, cultura y cambio social. Correo electrónico: carmen.paz@fec.luz.edu.ve

Fecha de recepción: 0311 17; Fecha de aceptación: 231117.
}

(cc) EY-NC-ND Páginas 277-288. 
por ejemplo, a un anciano o anciana referirse a ellos como "mi tío o mi tía", "mi abuelo, mi abuela" o ta’iru, talaüla, tatüshi, mảachon, respectivamente. Conozco la cultura wayuu — los mitos, creencias, ritos, valores, normas, costumbres, modos de pensar, de sentir y de actuar- Los inconvenientes de mi situación: posiblemente no prestar atención a cosas cotidianas, no ver las contradicciones, las diferencias, la subjetividad — presente en todo investigador, pero más marcada cuando uno forma parte del grupo-y la tendencia a la reivindicación por sí misma.

En cada experiencia etnográfica me surgían interrogantes que han determinado mi experiencia como investigadora: ¿Cómo establecer la distancia y articular mi subjetividad en la elaboración de un conocimiento antropológico? ¿Podré ir más allá de la descripción anecdótica de los acontecimientos que forman parte de mi cotidianidad o los que me han tocado vivir? Este trabajo sobre el sueño en mi propia cultura, pues, es para mí un reto.

El sueño ocupa un lugar central en la resolución de situaciones que se presenta en la vida de mi cultura: la enfermedad, la previsión de situaciones difíciles que pueden venir. El sueño ocupa un lugar importante en la vida de mi familia. Cuando ocurre un suceso adverso —enfermedad, muerte, pérdidas, robos- siempre se buscan signos relacionados de cómo se habría evitado este acontecimiento a través de una señal transmitida mediante el mundo de los sueños.

Sólo me referiré, ahora, a los sueños que tienen que ver con la enfermedad en los niños. Tengo en cuenta un sueño ocurrido en mi niñez y el sueño de una curadora wayuu, hermana de mi abuela, en relación con una enfermedad que sufrí, conocida como apülainwaa. Estos sueños son contrastados con otros recogidos en el trabajo de campo.

Lapü es "Sueño". Hace referencia a la deidad que transmite mensajes a través de los sueños. Mediante él se pronostican muchos de los sucesos que acontecerán sobre salud, enfermedad, vida, muerte, de ahí que esta deidad sea fundamental para los oütshii, piaches o curadores wayuu, ya que mediante los sueños pueden diagnosticar, prescribir y pronosticar el desenlace de una enfermedad, acontecimiento adverso, situación negativa. Lapü ejerce su influencia en el presente y en el futuro. Todos 
los sucesos están marcados por él, por eso es temido y acatado en sus imposiciones. Sueños o Lapü está muy relacionado con los ciclos vitales de la persona y su destino. "Gracias a Lapü, a Sueños, nace el niño. Sueños tiene una manera de comportarse con el que nace, así como tiene una manera de comportarse con el que duerme y una manera de comportarse con el que muere"... Es gracias a Lapü que las personas tienen aa’in, energía vital de los wayuu. Es así como "el niño se forma con el pene, cuando el hombre toma a la mujer. Pero Sueños viene de noche y trae un poquito de alma (Perrin, 1995: 36). La acción de soñar o alapüjawaa no es dormir o atunkawaa. El sueño se concibe como la andanza nocturna del aảin o alma, la enfermedad como su divagación prolongada, y la muerte como su partida definitiva.

Para los wayuu, el mundo sagrado, como el mundo cotidiano, está lleno de ambivalencias y paradojas. Así, por ejemplo, los seres del mundo no humano son pülasü, tienen el poder de la vida y la muerte, de la salud y la enfermedad; de ellos se derivan todas las enfermedades. Lo "sagrado" para los wayuu es todo lo que califican de pulas ü, en oposición a lo que consideran anasü, lo cotidiano, lo cotidiano no peligroso, lo permitido. En el mundo de los sueños hay contactos de los vivos con el mundo del más allá, esto es con seres del mundo "sagrado" o pülasü. Están los espectros de los muertos, los yoluja. Son todas las personas que han muerto. Al morir un wayuu va a Jepira, considerado el sitio donde habita el wayuu muerto, en dicho lugar reposan otros wayuu que partieron mucho antes. Para los wayuu, cuando uno muere, el cuerpo físico muere, pero la a'in sigue viva, se transforma en yoluja, en no humano, que son siluetas imprecisas y sin huesos, muertos que residen en Jepira. Cuando una persona muere, es la imagen que puede aparecer en los sueños, se sigue comunicando con los vivos mediante el mundo de los sueños. Es así como "cada suceso es anticipado bajo la forma de reflejos o de sombra no esperadas en la cotidianidad" (García Gavidia, 2000: 690).

Las personas pueden ser víctimas de un yoluja: los espíritus, espectros de muertos recientes, no son considerados personas; pierden esa condición al morir y salen en la noche a dar vueltas, tratan de robar el alma o aa'in de los vivos. El yoluja se hace presente en la cotidianidad 
del wayuu: “...atacan de noche, los niños empiezan a llorar, más que todo a las seis de la tarde". Las personas que han sido asesinadas "son malos espíritus que se meten en el cuerpo". Estos yoluja molestan a los niños, "no los dejan dormir, así dicen, y entonces allí es que se lo llevan a los piaches para que les echen tabaco, los bañen con tabaco y esas cosas, porque el alma lo tiene pegado allí, lo molesta, dicen”. Cuando un wayuu, niño o adulto, sufre algo de repente y muere se dice que fue atacado, kalíashi, por un yoluja.

Pero además hay otros yoluja, generalmente espectros de familiares fallecidos, que intervienen mediante los sueños para ayudar a los vivos, protegerlos para evitar sucesos trágicos y recomendar terapias curativas. Es la continuidad, es un mundo que no es lejano ni ajeno a lo que ha sido su modo de vida.

Los yolujas o seres queridos que han muerto son entidades ambivalentes; tiene el poder de la contaminación, pero son espíritus benefactores:

Está con nosotros si a uno le va a pasar algo malo, así si uno siente que le va a pasar algo malo, uno sueña con alguien querido que ya partió. Por ejemplo, mi papá está muerto, hay veces que si me va a pasar algo malo, es como si me avisara. Cuando sueño con él me pongo preocupada de que si algo me va a pasar o a uno de mi familia, es como si fuera un aviso (Etelvina Montiel, 2002).

Los tres componentes de la persona son el cuerpo, el alma y los huesos. Según las costumbres y ritos wayuu, cada uno de los componentes tiene una función y un destino, se funden en un principio superior. De éstos, el cuerpo y los huesos se pierden al morir dos veces y dos veces se entierra a los muertos. Se distribuyen por Juya, Pulowi y Lapü — creadores del mundo y los seres vivos - bajo otra forma, por ejemplo, se convierten en lluvia o en wanülü̈̈, benefactores o espíritus auxiliares; los huesos son acumulados y mezclados en osarios con el segundo entierro, y representan a los antepasados y al linaje (Perrin, 1992).

Los conceptos del ser y la existencia de la vida en el universo de los wayuu se fundamentan en la distinción ontológica entre "materia" y "energía vital". Esta última proviene de aa in wayuu y habita en 
todos los seres vivos, plantas y animales. La aa'in está relacionada con la vida, la enfermedad y la muerte, es una unidad inalterable, su presencia o ausencia en el cuerpo produce la enfermedad o la muerte. Según los outshii, los curadores wayuu, del proceso de alejarse o acercarse del a'in va a depender el tipo de enfermedad y la forma de curación, y se hace presente en el wayuu de tres maneras: a) mediante los sueños, la aa in tiene un vagabundeo nocturno; b) cuando el wayuu se enferma, la aa in deambula prolongadamente, la enfermedad es un "desmoronarse del cuerpo a causa de la salida de la aa 'in"; c) cuando el wayuu muere, la $a a^{\prime}$ in se va — realiza un viaje — definitivamente al Jepira o lugar de los muertos, "ésta se vuelve a encarnar en el espectro, donde permanece intacta” (García Gavidia, 2000: 690).

La aa in tiene una formación compleja. En los primeros años de vida se va conformando. El wayuu adulto tiene su aa in centrada y consolidada, pero al final de la vida se va debilitando hasta que abandona el cuerpo. En este sentido, aa in es un componente de la persona que se desarrolla y fortalece a medida que el niño o la niña crecen. Este hecho explica los cuidados esmerados al nacer para evitar las enfermedades y otros acontecimientos. La fragilidad del niño, de su aảin, es la explicación dada por los wayuu a la mortalidad infantil. Afirman que el alma no se ha asentado definitivamente en el cuerpo, no hay una conexión fuerte todavía, por esta razón hay mucha fragilidad. A medida que el nińo va creciendo es más fuerte, a pesar de que la aa in no se ha asentado definitivamente, por eso no deja de ser presa fácil de las enfermedades.

Cuando la persona sueña, la aảin deambula y se encuentra con seres queridos que pueden darle mensajes refiriéndose a sucesos que podrían pasar y cuáles son las acciones que hay que hacer para que no se cumplan los sucesos adversos para algún familiar.

Los sueños forman parte de la vida cotidiana. Generalmente, entre los miembros de la familia y los amigos se dice jjamaya pülapüin?, ¿Cómo estuvo tu sueño? Para iniciar una conversación en torno al sueño. Pero no todos los sueños son iguales, depende de quién sueña y del mensaje que transmite sobre la acción a realizar en el mismo. Generalmente se sueña con un familiar "que falleció hace mucho tiempo, [y] te dice a ti para que te ayudes a ti misma o a otra persona, especialmente 
a niños; mira, fulano(a) tiene esto, pobrecito, hay que hacerle esto para que se mejore...”, explica la oütsü, la curadora Ana Andrade, mujer adulta que vive en Los Hermanitos, esposa de un tío materno.

La práctica del sueño descubre los diversos tipos de enfermedades. Las de tipo ayülee son enfermedades comunes que pueden ser superadas con plantas medicinales o con algún medicamento alopático, y las de tipo wanülüü ameritan la intervención de un curador wayuu o seguir los mensajes de algún sueño. Mediante el sueño se indican plantas medicinales, productos animales o minerales, y la combinación de terapias, como acudir a un curador. En las enfermedades de tipo wanülü̈̈ el tratamiento a seguir es transmitido por la persona que soñó, por un miembro del grupo doméstico o por el oütshi, que también lo ha recibido en sueños. Una parte de las prácticas curativas se realizan a partir del sueño, en el curso del cual se indica cómo curar enfermedades de un miembro del grupo y la manera de remediar situaciones mórbidas, tanto en las enfermedades de tipo ayülee como wanülü̈̈.

A continuación comento acerca de varios de mis sueños, de los sueños de mi familia y de una oütshii, también perteneciente a mi familia. En concreto, trabajaré con dos sueños, uno es el relacionado con una enfermedad que me afectó en mi niñez y que una oütsü le transmitió a mi madre. El segundo es un sueño mío, que tuve mucho tiempo después sobre los procesos de vida y muerte. Incorporo además otros sueños que hayan implicado la ejecución de algún rito relacionados con personas durante su niñez o con niños.

Este sueño ocurrió durante mi niñez. Quedó en mi memoria porque lo escuché muchas veces siendo niña y como adulta de boca de mi madre y de mi abuela. Este sueño ocurrió por una enfermedad denominada apülainwaa, que es causada por un animal contaminante. Según dice mi madre, "no podía caminar, gateaba, no comía, no hablaba y tenía sus manos apretadas", por ello mi apodo es precisamente "Maza'achon", la niña que no caminaba. En un primer momento mi madre acudió al hospital, los médicos tenían distintos diagnósticos, uno de ellos era polineuritis. Estaba muy débil. Pensaban que me moría.

Mi madre no estaba muy convencida del diagnóstico de los médicos. Ella pensaba que era apülainwaa, y esta enfermedad no la podrían 
curar los médicos, sino los piaches o öutshii. Una noche una tía de mi madre tuvo un sueño que le indicaba lo que tenía que hacer, por eso decidieron sacarme de inmediato del hospital. Este sueño indicó claramente a mi madre dónde tenía que buscar mi curación. Los médicos se opusieron y mi madre les dijo que si su hija se llegaba a morir, ella era la que la iba a llorar, la que iba a sentir el dolor, porque era "carne de su carne”. Ante mi enfermedad ella tenía que agotar todos los esfuerzos para llevarme a distintas opciones de sistemas curativos, en este caso el de su misma cultura. Su desesperación era grande. Ella misma argumentaba que yo era su hija mayor, que no me quería perder, que era "carne de su carne" porque pertenezco al eirrükü ipuana, y ella tenía la responsabilidad de cuidarme como miembro de su matrilinaje, porque mi vida garantizaba su descendencia.

Mi madre asumió que los hijos son carne de su carne, y que cualquier suceso trágico que le ocurra a alguno de ellos, especialmente a las mujeres que aseguran la continuidad de su linaje, afecta a todo su apüshi. Es un principio fundamental el reconocimiento del derecho de una madre sobre la hija y la responsabilidad que tiene la mujer con su matrilinaje.

Cuando le contaron el sueńo a mi madre, ella me sacó sin el consentimiento de los médicos del hospital, pero había señales de que todo iba por buen camino. La curadora me recibió con una aspersión de licor, el sueño le indicó que si mi cuerpo reaccionaba a esta señal estremeciéndose ante el soplo del licor chirrinchi —licor artesanal wayuu - , yo me iba a salvar.

El soplo efectuado era una señal de salvación; significaba la protección de mi cuerpo y aảin por los aseyuu o espíritus auxiliares de la curadora. Mi cuerpo se fue restableciendo poco a poco. Sólo faltaba el tratamiento, el cual fue trasmitido mediante los sueños sucesivos a la curadora. Según su diagnóstico era una enfermedad apülainwaa por causa de un animal, el báquiro — una especie de cerdo salvaje-. Los aseyuu le dijeron en sueńos a la oütsü que cuando mi madre estaba embarazada comió maíz jojoto — maíz tierno, inmaduro- que había sido comido por ese animal. Es así como fue contaminada y me lo transmitió a mí. 
La explicación de mi conversión en báquiro se basó en el hecho de que mi mano se empuñaba como la pezuña de este animal que fija su pezuña de forma dura sobre la tierra. Además, me dio parálisis en las extremidades inferiores, no me podía poner de pie como todos, sino que me arrastraba, gateaba y no podía sostenerme de pie, lo cual indicaba también la similitud con el animal. De hecho, tuve un proceso de reaprendizaje para volver a caminar, me caía constantemente; mis manos tampoco tenían equilibrio, una de las cosas que recuerdo es que no podía ni ensartar una aguja, las manos me temblaban.

Por medio de los espíritus auxiliares la oütshi establece el diagnóstico e indica el tratamiento a seguir, dictado en el sueño en el cual los espíritus le comunican al curador las causas y lo que debe hacerse para restablecer la salud. En los sueños de los oütshii se manifiesta la comunicación con los espíritus. En las terapias realizadas se evidencia la eficacia de la práctica curativa indicada en los sueños.

Habitualmente estos tratamientos implican dos procesos a) la negociación del aai in —alma—, b) La práctica curativa realizada con el animal contaminante. De ahí se infiere el reconocimiento y las posibilidades de curación del enfermo. A mi madre, Lilia Paz, le indicaron los curadores, según ella me ha explicado, que "parándose la niña queremos ver a una becerra blanca con las pintas negras, que apenas esté destetada”. Había que amarrarla debajo de una mata, tal como se lo indicaron en sueños. Mi padre, sigue explicando mi madre, estuvo un día buscando un animal con esas características, y lo consiguió. Tal como lo había visto en los sueños mi tía, la curadora amarró la becerra debajo de un árbol, y en ese mismo instante yo empecé a reponerme.

En los sueños se aplica el principio de homología, lo igual cura lo igual, la vaca es valorada por los wayuu y es utilizada en los diversos ritos relacionados con la muerte, en el matrimonio, en el nacimiento de un niño. Vale señalar que la sociedad wayuu desde la época de la llegada de los españoles a estas tierras, adoptó el modo de vida pastoril. Es así como el ganado es parte importante en el mundo de los sueños para ejecutar acciones relacionadas con los mismos (Perrin, 1987: 4). En el mundo wayuu el ganado doméstico tiene una importancia muy grande: ganado y familia humana son casi equivalentes. "Las clave guajiro de 
los sueños establece una verdadera correspondencia, término a término, entre las diversas clases de animales domésticos y los hombres, según la edad, sexo y estatus social" (Perrin, 1987: 25) Es así como el mundo más allá de los vivos equivale la carne de ganado con la carne humana, es el eirrükü que designa a la carne —alimento_-, la carne humana y al matriclan. Esta es una de las explicaciones del sacrificio de ganado en los velorios wayuu, tener un buen entierro es sacrificar mucho ganado, y asimismo ese ganado sacrificado será el rebaño del muerto en Jepira o paraíso de los muertos. Es así como se puede asociar el principio de homología entre una becerra y una niña apenas destetada. Con cinco años no habían trascurrido muchos ańos del destete, e igualmente, la becerra es la cría de la vaca que no pasa, o pasa muy poco, de los dos años.

Esta primera acción señala el inicio del reencuentro con el aa in o alma para restablecer el equilibrio perdido. Estuve en una fase liminal, muy cercana a la muerte, y por ello fue necesario realizar una segunda acción que implicó al animal contaminante. Mi madre me contó que seguidamente fue necesario encontrar un báquiro: "después de cumplir con lo que habían solicitado, había que buscar un báquiro en el monte". Me dieron de comer carne del animal e hirvieron la piel, y con el agua caliente me sobaron por una semana. Me restablecí completamente. Al cumplir con los espíritus auxiliares, se hace el tratamiento al pie de la letra, se restablece el equilibrio causado por el animal contaminante o por cualquier otro agente.

La contaminación por animales se da comiendo el animal o sus productos. Los oütshii son los que descubren el nombre del animal responsable y prescriben el tratamiento adecuado. Es decir, las analogías fundan las etiologías y los tratamientos. Se presume que hay una relación causal entre el animal y la enfermedad a la que se asocia: es tan grande la semejanza entre tal o cual síntoma y tal o cual rasgo de animal que no puede ser sino el efecto de este animal en el cuerpo del niño o de la parturienta. En el caso de mi enfermedad, mi madre me contaba... "estabas empuñando la mano muy fuerte, se estaba poniendo dura como la pezuña del animal y tampoco podías caminar".

En los sueños relacionados con los niños, la mayoría de las veces presagian, previenen o tratan las contaminaciones o enfermedades 
apülainwaa. Éstas incluyen: contaminación por animales, contaminación por homicidas y sus víctimas, contaminación por la persona que ha manipulado cadáveres de víctimas asesinadas, contaminación por quienes han manipulado cadáveres exhumados en el rito del segundo velorio, contaminación de objetos relacionados con la muerte.

Soy la mayor de cuatro hermanos. Cuando era niña recuerdo que estaba íntimamente unida a mi abuela. La enfermedad anteriormente seńalada la recuerdo con muy poca consistencia, porque tendría unos cinco años. Mis familiares me contaban que en el hospital sólo tenía consuelo al estar con mi abuela, cuando ella se ausentaba referían que sufría mucho y lloraba desconsoladamente hasta que ella aparecía. Quizás esta unidad con este ancestro femenino permitió el siguiente sueño.

Tenía siete años cuando me encontraba en la comunidad donde vive actualmente mi madre, en los linderos de su casa, porque las casas no son tan cercanas con respecto a las otras, hay pozos de agua, corrales para ovejas, cerdos y vacas. Y un espacio en el que hay plantas de cujies (Acasia farnesiana), coco (Cocos nucifera), uva de playa (Coccoloba uvifera), entre otras. Justo después de las plantas había un jagüey que se llenaba en la época de lluvias e iniciaban unos médanos. Del lado hacia donde estaba mi vivienda, en dirección oeste, estaba una señora con manta wayuu que me llamaba, a esta mujer luego la identifique en fotos, se trataba de mi bisabuela quien me estaba haciendo seńas de que fuera hacia donde ella estaba en lo alto del cerro. Empecé a caminar hacia ella, cuando llevo como un metro, del otro lado donde empecé a caminar me llamó mi abuela con quien estaba íntimamente unida. Cuando volví a mirarla decidí regresar con ella, luego ella me abrazó y me tomó por la mano. Y con la otra mano le hacía una señal de adiós a mi bisabuela muerta, quien respondió con los brazos abiertos.

Este sueño representa para mí una gran metáfora onírica, un viaje hacia la muerte que no se dio. En la otra orilla me esperan mis familiares muertos, pero en ese momento no hice ese viaje. Mi bisabuela del matrilinaje ipuana me estaba esperando para llevarme con ella. Este sueño es claramente descifrable desde la perspectiva del mundo wayuu, en él se mezclan los orígenes, la matrilinealidad wayuu y las referencias familiares ligadas a la vida y a la muerte. Ir de un extremo 
a otro simbolizaba el conservar la vida o ir a la muerte. Cuarenta años después, aún sigo viva. Considero que este fue un sueño para no morir y apostar por la vida. Pienso que mientras no me busque alguno de mis familiares que se comunican constantemente a través de los sueńos podré seguir construyendo mi vida y destino. Las claves de los sueños en el pueblo wayuu constituyen "un sistema relativamente abierto, la interpretación puede variar según el contexto”, es decir, cambian en el transcurso del tiempo, son flexibles, extensivos, según los cambios y las modas (Perrin, 1990: 96).

Los wayuu explican que si el niño ha pasado por una enfermedad del tipo apülainwaa, el alma o a 'in se vuelve fuerte y son menos susceptibles de enfermarse por esa causa. Hay que estar muy pendiente de los sueños y realizarlos para fortalecer su aảin. Cuando una persona ha padecido pulaüwa en la niñez tiene, según los ancianos wayuu, una larga vida, parece que al pasar por la enfermedad se vuelven más fuertes en su aa in, de ahí que "ya llegarán a alaüla”, dicen los viejos.

Es importante compartir los sueños cada vez que te encuentras con los familiares y allegados, sólo hay que dedicar un tiempo y preguntar jjamaya pülapuin? Y estar abierto para escuchar y hacer los sueños.

\section{Bibliografía citada}

García Gavidia, Nelly, 2000, "Los significados sociales de la enfermedad: Qué significa curar”, Tierra Firme, núm. 72, pp. 683-69, Caracas.

Perrin, Michel. 1987. "Creaciones míticas y representación del mundo: el ganado en el pensamiento simbólico Guajiro”, Antropológica, núm. 67, pp. 3-31.

Perrin, Michel, 1990, "La lógica de las claves de los sueños. Ejemplo guajiro", en Michel Perrin (coord.), Antropologías y experiencias del sueño, Ediciones Abya-yala, Quito.

Perrin, Michel, 1992, El camino de los indios muertos, trad. Fernando Núnéz, Monte Ávila Editores Latinoamericana, Caracas.

Perrin, Michel, 1995, Los practicantes del sueño. El chamanismo wayuu, Monte Ávila Editores Latinoamericana, Caracas. 